\title{
Industry Self-regulation Under Government Intervention
}

\author{
Juan P. Mendoza ${ }^{1}$ (D) Henri C. Dekker ${ }^{1} \cdot$ Jacco L. Wielhouwer $^{1}$
}

Published online: 20 August 2019

(C) The Author(s) 2019

\begin{abstract}
Objective Industry actors (organizations, associations) can influence the way in which firms comply with regulations. This study examines how this influence process is affected by government intervention.

Methods Using official, anonymized data from the entire industry of financial intermediation in the Netherlands $(N=8655$ firms), we examine how firms' affiliations with industry actors relate to (1) voluntary actions aligned with improving regulatory compliance (e.g., requesting audits, attending workshops), and (2) law violations. Industry actors are distinguished between trade associations and the industry's self-regulatory organization (SRO), which is subject to more government intervention. The analysis employs Poisson regressions to explain count variables, and bootstrapping to assess indirect associations. A series of robustness tests focus on relevant sub-samples, employ exact matching to address possible self-selection, and incorporate lagged dependent variables.
\end{abstract}

Results The association between affiliations with industry actors and law violations is negative and significant. This association is more indirect for trade associations than for the SRO (i.e., it is more strongly mediated by the voluntary actions firms take and which help to improve compliance).

Conclusions These findings go in line with the theory that government intervention makes industry-self regulation more mandated and less voluntary. Under less government intervention, industry actors may promote more voluntary efforts to comply.

Keywords Firm compliance · Industry self-regulation · Government intervention

\section{Introduction}

In a diversity of settings, firms can join industry organizations or associations. Industry self-regulation (ISR) broadly refers to the influence that these industry actors exert on firm regulatory compliance. Numerous studies have examined why ISR can be effective or ineffective (e.g., Barnett and King 2008; Lenox 2006; Short and Toffel 2010). This is a critical issue for criminologists and policymakers, as there is great value in identifying why

Juan P. Mendoza

j.mendozarodriguez@vu.nl

1 School of Business and Economics, Vrije Universiteit Amsterdam, De Boelelaan 1105,

1081 HV Amsterdam, The Netherlands 
collectives of private actors can contribute to the promotion of desirable firm behavior and to the reduction of public enforcement and supervision costs (Crawford 2006; Drahos and Krygier 2017; Haufler 2013).

There are two views on this topic. The economics view indicates that, in order to enforce compliance, industry actors must rely on deterrence and have the power to detect and sanction non-compliant firms (Ashby et al. 2004; King and Lenox 2000; Lenox and Nash 2003). The institutional view indicates that industry actors can use other mechanisms, such as active communication and guidance, to enhance normative motivations and support social dynamics that promote voluntary compliance (Gunningham and Rees 1997; Haufler 2013).

The role of the government can be critical in this context, as it can influence how both industry actors and firms behave. The government can intervene, for example, by setting rules and objectives for industry actors, or by granting them legal powers to monitor and sanction firms (Gupta and Lad 1983). As government intervention increases, researchers categorize ISR as more mandated, or equivalently, as less voluntary (Black 2001; Bartle and Vass 2007). The argument is that increased government intervention makes industry actors behave more as representatives of the authorities, and rely more on deterrence to enforce compliance. As a result, compliance becomes relatively more of a mandate or an obligation, and relatively less of a free and independent choice. For firms, it is not the same to respond to the threat of punishment for non-compliance than to, for example, act under the understanding that compliance is a justified and sensible thing to do (Gunningham and Rees 1997; Parker and Nielsen 2011; Tyler 2011).

In this study, we examine how government intervention affects the way in which industry actors exert influence on firm compliance. Our motivation is that government intervention creates an interesting tension: it can determine how industry actors promote enforced versus voluntary behavior. This goes in line with modern debates about enforcement dilemmas and policy trade-offs (Feldman 2018), as it challenges the intuition that, when it comes to intervention and control, more is necessarily better.

Our departure point is that industry actors can motivate firms to take voluntary actions that help them attain higher levels of compliance (e.g., requesting audits, attending workshops and training sessions). Based on this, we formulate two hypotheses. The first is that ISR can be effective independently of the degree of government intervention. If industry actors can motivate firms to make voluntary efforts to comply, a high degree of government intervention is not a necessary condition for effective ISR. The second hypothesis is that, under less government intervention, ISR is more strongly supported by the promotion of voluntary efforts to comply.

To test these hypotheses, we obtained access to official anonymized data from the entire industry of financial intermediation in the Netherlands $(N=8655$ firms $)$. Financial intermediaries sell and provide advice on financial products, such as mortgage credit and life insurance. As in various other settings, firms in this industry can voluntarily join the industry's self-regulatory organization (SRO) and various trade associations. ${ }^{1}$ As compared to trade associations, the SRO is subject to a higher degree of government intervention. The analysis focuses on how being affiliated with each type of industry actor relates to (1) voluntary actions aligned with improving regulatory compliance, and (2) law violations. We employ Poisson regressions to explain these two count variables, and bootstrapping to

\footnotetext{
1 In this study, we refer to trade associations, which are also known as business, branch, sector or industry associations, bodies or organizations.
} 
assess mediation (i.e., the indirect association between affiliations and compliance that is channeled through voluntary actions). We conduct a series of robustness tests, which focus on relevant sub-samples, employ exact matching procedures to mitigate the influence of self-selection, and include lagged dependent variables (which indicate whether firms are, for example, structurally less compliant).

The results support our hypotheses. Being affiliated with each type of industry actor is negatively associated with the number of law violations, although in different ways. The association between being affiliated and law violations is more indirect for trade associations than for the SRO (i.e., it is more strongly mediated by voluntary actions). This indicates that a high degree of government intervention may not be a necessary requirement for effective ISR.

These findings go in line with the theory that government intervention makes ISR more mandated and less voluntary (e.g., Black 2001; Gunningham and Rees 1997). They are not meant to suggest that ISR is always possible, that a given degree of government intervention is preferred over another, or that industry actors are better or worse than the authorities at promoting regulatory compliance. The key point, instead, is that the degree of government intervention may be associated with the process through which industry actors promote compliance. ISR may be effective under different degrees of government intervention. What may vary, however, is the means or the path through which industry actors exert influence on compliance.

Authorities that seek to maximize compliance at the lowest cost benefit from external actors that safeguard or enhance firms' voluntary efforts to comply, as this is equivalent to outsourcing regulatory tasks (O'Rourke 2003). From this perspective, government intervention is costly not only when it requires valuable resources (e.g., specialized technologies, facilities, or personnel), but also when it affects firms' voluntary efforts to comply. These potential trade-offs should be taken into account when deciding on whether to intervene. We elaborate more on the implications and limitations of our analysis in the "Discussion" section.

\section{Theory and Hypotheses Development}

\section{Industry Self-regulation}

The literature provides various definitions and classifications of ISR, but in general this term refers to the influence that industry actors exert on firm behavior (e.g., Black 2001; Gilad 2010; Haufler 2013). Influential studies in this area refer explicitly to distinct industry-level actors, as opposed to government-level or firm-level actors (Gunningham and Rees 1997; Gupta and Lad 1983), and employ verbs that imply influence, such as "control", "monitor", and "regulate" (e.g., King and Lenox 2000). Although industry actors may promote a diversity of behaviors (e.g., adhering to quality standards or duties of care), the literature has given particular attention to firm regulatory compliance.

The theory describes different ways in which industry actors exert influence on compliance. Economists suggest that effective ISR requires deterrence and enforcement (i.e., the credible threat of punishment for non-compliance; Ashby et al. 2004; DeMarzo et al. 2005; Maxwell et al. 2000; Nunez 2001). With the power to monitor firms and impose sanctions, industry actors are able to deter opportunistic behaviors that make ISR ineffective (King and Lenox 2000; Lenox 2006; Lenox and Nash 2003). Without deterrence and 
enforcement, however, industry actors attract non-compliant firms that seek to hide their poor performance (an adverse selection problem), or allow member firms to comply less while benefiting from the compliance of others (a free-riding problem).

Institutionalists suggest that effective ISR is also possible without deterrence. Industry influence can operate as a system of informal social forces, which promotes standards and practices of desirable conduct (Pfarrer et al. 2008). More specifically, researchers identify normative, coercive, and mimetic forces, which relate to, for example, the promotion of industry norms and values, the public exposure of misconduct (naming and shaming), and the transfer of best practices, respectively (King and Lenox 2000; Lenox and Nash 2003).

With regard to normative forces, it is assumed that firms and industry actors are not only driven by self-interest and economic gains, but can also be motivated by ideals, principles, and values (Gunningham and Rees 1997; Nielsen and Parker 2012; Tyler 2011). Industry actors have the capacity to establish normative frameworks, and take actions to institutionalize a sense of industrial morality (Gunningham and Rees 1997). For instance, industry actors can set guidelines for corporate governance structures or codes of conduct that seek to protect the interests of stakeholders (e.g., employees, local communities, customers, suppliers). In this way, they are able to reinforce and further legitimize a sense of responsibility across member firms.

The economics and institutionalist views on firm compliance can resemble the criminological theories of rational choice and informal control at the individual level of analysis. Although we have reviewed theories about firm-level motivations and behavior, it is important to acknowledge the role of the individuals inside the organization (Hansen 2009; Schell-Busey et al. 2016; Simpson and Rorie 2011). This distinction is evidently recognized in practice. While firms pay fines or get sanctioned, firm representatives can be held responsible for corporate misconduct. Indeed, deterrence and informal social forces can also operate at the individual level, altering the motivations and behaviors of owners, executives, and employees. For example, industry associations and organizations can help form and maintain communities of practice (Wenger 1999) among CEOs, internal auditors, compliance officers, and members of boards of directors, who may share concerns about corporate misconduct or interests in updating regulatory requirements, in response to technological advances or particular events. Industry actors may serve as physical or virtual platforms where practitioners connect, exchange views and opinions, and share observations from what they learn in practice.

\section{Government Intervention}

One common observation across the literature is that ISR can be classified based on the degree of government intervention (Bartle and Vass 2007; Black 2001; May 2005; Sinclair 1997). For example, the government intervenes when it sets rules and objectives for industry actors, monitors their operations directly, or delegates monitoring and enforcement responsibilities to them (i.e., through government-imposed regulatory mandates; Wotruba 1997). With this in mind, researchers have proposed to classify ISR within a government intervention continuum. Garvin (1983; p. 48) refers to a "regulatory spectrum", which has autonomy of individual firms in one direction and degree of government intervention in the opposite direction. Gunningham and Rees (1997; p. 366) refer to a "continuum", which has pure self-regulation (without any intervention) and government regulation at opposite ends. Similarly, Sinclair (1997; p. 532) refers to a "regulatory continuum", which has pure selfregulation (voluntary deference) at one end and strict command and control (deterrence) at the opposing end. 
This classification is based on two key assumptions. The first is that, under less government intervention, compliance is more independent, autonomous, and voluntary (Black 2001; Fairman and Yapp 2005). Through the above-mentioned normative, coercive and mimetic means, industry actors are able to safeguard or even enhance firms' motivations to comply on a voluntary basis, independently of the government's deterrence and enforcement. These motivations may relate to, for example, having a sense of civic duty, an interest in establishing good public relations, or a strong preference for maintaining a positive reputation (May 2005; Parker and Nielsen 2011; Tyler 2011).

The second key assumption is that more government intervention involves relatively more deterrence and enforcement. By delegating legal monitoring and sanctioning powers, or by instructing industry actors to incorporate compliance as a membership requirement, the government draws increased attention toward deterrence and enforcement. The activation of deterrent fears pushes firms to comply relatively more as an obligation and relatively less as a free and independent choice (May 2005).

In principle, compliance can be attained at all possible levels of government intervention. The continuum is used to describe how government intervention changes the influence that industry actors exert, and ultimately affects firms' motivations to comply.

\section{Hypotheses}

The literature identifies the means through which industry actors exert influence on compliance. It can be theorized that the influence through deterrence is relatively more immediate and direct than through alternative mechanisms. For instance, industry actors can promote responsible codes of conduct, which in turn motivate firms to make efforts to comply (i.e., an influence process that goes in steps). In general, the influence through alternative mechanisms can be considered indirect as it first motivates firms to take voluntary actions (e.g., requesting audits, attending workshops), which in turn helps firms attain higher levels of compliance. Based on this conceptualization, Fig. 1 depicts how being affiliated with industry actors can have direct and indirect effects on regulatory compliance. The indirect effect is channeled through the voluntary actions firms take in order to improve compliance.

Following recent advances in mediation analysis (Zhao et al. 2010), ISR can be considered effective when being affiliated with industry actors has a positive and significant effect on compliance, directly or indirectly ( $c>0$ or $a \cdot b>0$ ). This effect can be fully, partially, or not mediated by voluntary actions.

In this study, we are interested in examining how government intervention affects ISR, and more precisely, the path through which industry actors exert influence on compliance.

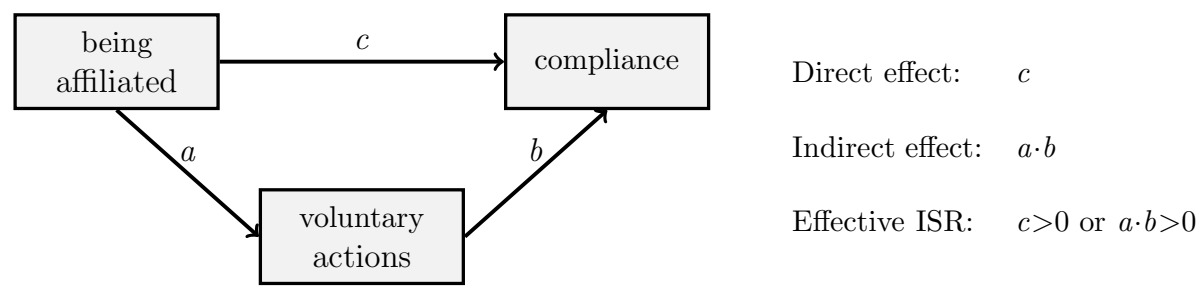

Fig. 1 Direct and indirect effects of being affiliated with industry actors on regulatory compliance 
Prior studies provide some indication. Qualitative research indicates that a higher degree of government intervention-by threatening to introduce tighter regulatory requirementscan make ISR more effective (Héritier and Eckert 2008). Quantitative research indicates that a higher degree of deterrence-having the power to conduct inspections and impose sanctions-makes ISR effective (King and Lenox 2000; Lenox and Nash 2003; Short and Toffel 2010). Moreover, researchers infer that voluntary compliance is possible. The arguments are that, in practice, compliance (1) tends to be higher than what deterrence theory predicts, (2) does not necessarily respond to the perceived risk of punishment, and (3) varies considerably among firms that are exposed to similar regulatory regimes (Gunningham and Kagan 2005; Sinclair 1997).

With this in mind, we formulate two hypotheses. The first is that ISR can be effective (i.e., being affiliated with industry actors can have a positive effect on compliance), independently of the level of government intervention. If industry actors can promote voluntary efforts to comply, a high degree of government intervention is not a necessary condition for effective ISR. Our second hypothesis is that (1) under more government intervention, the direct effect on compliance is relatively stronger, and (2) under less government intervention, the indirect effect on compliance is relatively stronger. In short, as government intervention increases, ISR is less likely supported by the promotion of voluntary actions.

\section{Setting}

To test these hypotheses, we analyze official data from the entire industry of financial intermediation in the Netherlands. Financial intermediaries sell and provide advice on various financial products, such as mortgage credit and life insurance. Firms in this industry face conflicts of interest, however, as they can profit from selling products that do not match their customers' financial capacity or needs (a practice known as misselling; Bolton et al. 2007; Inderst and Ottaviani 2009). Regulations seek to prevent misselling behavior, guarantee the provision of sound advice to potential customers, and in general promote market transparency and stability (Greenbaum et al. 2015).

\section{The Regulatory Authority}

The Authority for the Financial Markets (AFM) is responsible for supervising the conduct of the financial market sector in the Netherlands (AFM 2018). Supervision involves inspections, enforcement, and transfer of standards. When a breach is identified, the AFM can issue instructions or public warnings, withdraw licenses, cancel registrations, and impose fines.

As part of its supervision strategy, the AFM requires financial intermediaries to submit a mandatory self-assessment on a yearly basis, which is used to gather detailed information about, for example, financial products offered, employees, and financial indicators. The AFM can analyze combinations of responses to multiple items in the self-assessment and in this way determine whether firms are in compliance with specific regulations. For example, an exact combination of responses to different items can be used to establish whether a mandatory procedure is followed appropriately, a required certification has been obtained, or a given system is correctly in place (the confidentiality agreement prevents us from providing a more detailed description of the compliance assessment procedure and the 
regulations that it includes). Referring directly to the legislation, the AFM defines clear-cut rules to establish which combinations of responses indicate compliance versus non-compliance for each specific regulation. Computer software calculates the number of law violations per firm based on these rules.

This compliance assessment method is considered advantageous in this setting. Firms cannot immediately infer from individual questions which specific regulations are being subject to assessment, or which items and combinations of responses are used to assess compliance. Moreover, the compliance assessment procedure can be considered relatively more objective and comprehensive than other alternatives (e.g., self-reports containing subjective perceptions of compliance). In the self-assessment, the AFM requests a top representative of the firm to declare that all information has been reported accurately and truthfully (e.g., the chair of the board, the CEO). The AFM also informs firms that the reported information can be subject to an audit, and that there are penalties associated with fraudulent reporting.

\section{Industry Actors}

We examine the potential influence of two types of industry actors: the industry's self-regulatory organization (SRO) and trade associations. The SRO, named Stichting Financiële Dienstverlening, was founded as a private organization by financial intermediaries in 2006, and operated until 2012. It was legally defined as an autonomous administrative body. The AFM delegated two concrete tasks to the SRO: the provision of assistance with licenses and registrations, and the administration of the mandatory self-assessment among its members. Firms joining the SRO received a (limited) discount on license fees. The SRO also had the legal obligation to report firms that missed the self-assessment deadlines, intentionally reported inaccurate information, or were in severe violation of the regulations. Depending on the seriousness of the offense, firms could be expelled from the SRO.

Trade associations group financial, pension, or retirement advisors, or specialists in mortgage advice or financial planning, among others. They generally charge a membership fee, and pursue multiple objectives, with varying degrees of emphasis on regulatory compliance. For instance, some trade associations seek to represent the interests of member firms by promoting changes in the legislation, while others focus exclusively on the certification of quality standards.

There are several reasons why the SRO and trade associations can be treated as distinct industry actors. Only the SRO has mandated objectives and responsibilities, which include the legal obligation to report non-compliance. As compared to trade associations, the SRO is subject to more government oversight, and focuses more exclusively on promoting regulatory compliance. In this sense, the influence of the SRO is relatively more formal and centralized, whereas the influence of trade associations is relatively more informal and decentralized (Barnett and King 2008; Braithwaite et al. 1987). The SRO operates as one central node in the network, which directly represents the authority, and focuses more on communicating information about regulatory requirements through more standardized and unidirectional means (e.g., periodic instructional letters). Trade associations, in contrast, operate more as clusters of firms, and serve as platforms of more diverse and fluid means of communication (e.g., as physical and virtual forums in which member firms post questions and answers, and share experiences and opinions). 


\section{Method}

To obtain a clear understanding of the regulatory setting, self-assessment instrument, and compliance assessment procedure, we carried out multiple on-site discussions with representatives of the AFM and the SRO. We also discussed how the empirical measures were constructed, as a means to obtain external validation for the methods that we employed. The results of our analyses were presented to division managers and directors at the AFM.

\section{Data}

To construct the dataset required for this analysis, we approached the AFM and the SRO independently. Both parties granted us access to fully anonymized responses to the selfassessment, under strict confidentiality agreements. In addition, the AFM granted us access to the outcome of the official compliance assessment (i.e., number of law violations per firm). Anonymous firm identifiers allowed us to construct an integrated dataset, containing self-assessment responses and number of law violations of all the firms in the industry.

The analysis is based on the most recent observations we have access to, which are from 2010, the year before the SRO started the process to be terminated. As a means to control for the possible influence of self-selection (Gamper-Rabindran and Finger 2013; Lenox 2006; Lenox and Nash 2003), the analysis includes matched-sample tests, and a test that incorporates data from 2009, which allows us to control for unobserved factors and assess whether the results hold over and above prior behavior. A detailed description of all tests is presented in the "Analytic Strategy" section.

\section{Measures}

The constructs presented in Fig. 1 are operationalized as follows. Compliance is measured as the number of law violations (lower values indicate higher compliance). Law violations may relate to, for example, not having a required license to sell a specific financial product, or not implementing an adequate system to handle customer complaints. After integrating the data provided by the AFM and the SRO, we identify 12 regulations that were subject to assessment in $2010 .^{2}$ The number of law violations is therefore treated as a count variable, ranging from 0 to 12 . To further examine the quality of this measure, we requested AFM representatives to provide an indication of the seriousness of each offense. All law violations were defined as serious, and eight of them as highly serious. ${ }^{3}$

Voluntary actions refer to non-mandatory actions firms can take, and which can help them attain higher levels of compliance. The dataset contains information indicating whether firms took each of the following five actions: requesting a voluntary audit by an expert, attending workshops or training sessions, attending informational meetings,

\footnotetext{
2 The AFM and the SRO administered the same self-assessment, but the AFM had the capacity to add extra items when considered relevant. In 2010, this led to a difference in the total number of regulations assessed (12 for SRO members, and 15 for non-members).

3 Violating one law can result in numerous delinquencies. For example, not being transparent about conflicts of interests constitutes one law violation, but affects the advice given to numerous customers. Depending on the severity of each offense, the AFM can issue public warnings, place institutions under undisclosed custody, withdraw licences, cancel or refuse registrations, file reports with the Public Prosecution Service, or impose fines and orders for periodic penalty payments (AFM 2018).
} 
purchasing written material with specialized information, and subscribing to newsletters. Voluntary actions is treated as a count variable, ranging from 0 to 5 . It is important to note that each of these actions involves interactions with third parties-other than the SRO or any of the trade associations. This means that all the firms in the industry can take one or more of these actions, regardless of whether they are members or non-members of any organization or association.

In 2010, firms had the possibility to join the industry's SRO and 16 trade associations. We make a distinction between being affiliated with the SRO and being affiliated with trade associations, as these two industry actors are subject to more versus less government intervention, respectively. Being affiliated with the SRO is measured as a dichotomous variable taking the value 1 if the firm is affiliated, and 0 otherwise. Being affiliated with trade associations is measured as a dichotomous variable taking the value 1 if the firm is affiliated with one or more trade associations, and 0 otherwise. It is important to note that firms can be affiliated with the SRO only, trade associations only, neither of them, or both. To make a more stringent comparison, the analysis includes alternative tests which exclude firms affiliated with both types of industry actors (a mutually exclusive comparison), and firms affiliated with more than one trade association (a one-to-one comparison).

Considering that compliance might be influenced by firm characteristics (Parker and Nielsen 2011), the analysis includes the following control variables: number of employees, sales, types of financial products offered, and total range of products offered (as handling specific types or a larger number of products could demand more resources or generate more difficulties to comply). Number of employees is measured as the natural logarithm of full-time employees. We use a scale designed by the AFM to locate sales within intervals (e.g., €50,000-€100,000). Sales is measured as the natural logarithm of the midpoint of the interval. Each type of financial product-damage insurance, life insurance, mortgage credit, consumer credit, and investment property - is coded as a dummy variable taking the value 1 if the firm sells or provides advice on that product and 0 otherwise. Investment property is sold by less than $1 \%$ of the sample, so we exclude it from the regressions. The most common product type, damage insurance, is treated as the reference category, so that it is captured by the regression intercept. Product range is equal to the sum of the five product type dummies. In an additional test we include lagged dependent variables to control for unobserved structural factors.

\section{Analytic Strategy}

To test our hypotheses, we use the mediation model depicted in Fig. 2. The variables being affiliated, voluntary actions, and law violations are treated as the explanatory, mediator, and outcome variables, respectively. Hypothesis 1 predicts a negative and significant effect for each type of affiliation, which can be direct or indirect. Hypothesis 2 predicts a stronger direct effect for the SRO, and a stronger indirect effect for trade associations.

Figure 2 depicts a mediation model with two different explanatory variables. Empirically, the mediation model comprises two regressions examining the effect of each type of affiliation on voluntary actions (regression 1) and on law violations (regression 2). Each regression makes the distinction between being affiliated with the SRO, which is subject to more government intervention, and being affiliated with trade associations, which are subject to less government intervention.

Following methodological recommendations in criminology, we run Poisson regressions to estimate the effects on these two count variables, and report incidence ratios to 


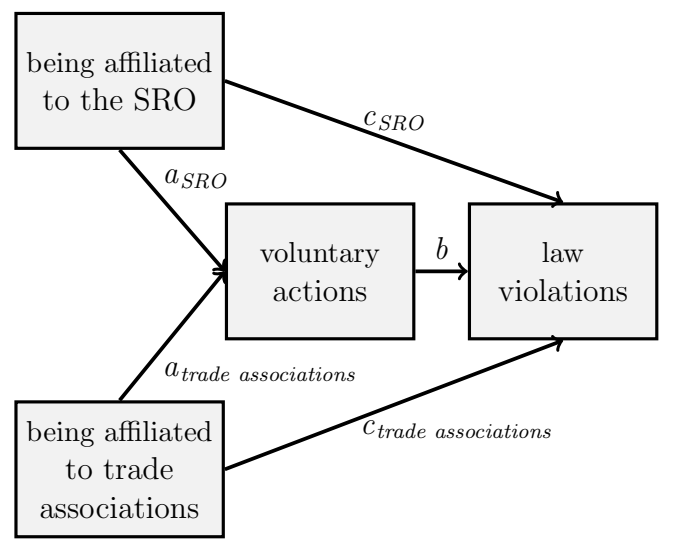

H1a: Effective ISR for the SRO: $c<0$ or $a \cdot b<0$.

H1b: Effective ISR for trade associations: $c<0$ or $a \cdot b<0$.

H2a: Stronger negative direct effect for the SRO:

$c_{S R O}<c_{\text {trade associations }}$.

H2b: Stronger negative indirect effect for trade associations: $(a \cdot b)_{\text {trade associations }}<(a \cdot b)_{S R O}$.

$\mathrm{H} 1$ and $\mathrm{H} 2$ refer to Hypothesis 1 and 2, respectively.

Fig. 2 Hypothesized effects of being affiliated with industry actors on (1) voluntary actions and (2) law violations

facilitate the interpretation of the results (MacDonald and Lattimore 2010). We assess the significance of the indirect effect using $95 \%$ bias-corrected and accelerated bootstrap confidence intervals, based on 5000 replications (as recommended by Coxe and MacKinnon 2010; MacKinnon et al. 2007; Preacher 2015). The same bootstrapping technique is used to compare the direct and indirect effects (i.e., to assess whether the expected differences are statistically different from zero).

The baseline model, referred to as Model 1, employs data from all the firms that were active in $2010(N=8655)$. The analysis includes alternative (robustness) tests that focus on relevant sub-samples or employ additional data to mitigate the potential influence of self-selection and omitted variables. The objective is to assess whether the results of Model 1 hold when we make more stringent comparisons. Considering that there is only one SRO, Model 2 excludes firms that are affiliated with two or more trade associations, as the observed differences could be explained by the number of trade associations, and not by the theorized qualitative distinction between the two types of industry actors (i.e., the observed differences should hold when firms are affiliated with not more than one industry association). Model 3 excludes firms that are affiliated with both types of industry actors, as this allows for a more clear-cut comparison (i.e., firms in this sub-sample can be affiliated with neither of the industry actors, either one or the other, but not both industry actors).

Following recent research in quantitative criminology (Cochran et al. 2016; PinaSánchez and Linacre 2014), Models 4 and 5 employ an exact matching technique that mitigates the possible influence of self-selection. Exact matching allows us to identify pairs of firms that are identical across all covariates, and which only differ in terms of being affiliated versus unaffiliated with each industry actor. The advantage of this exact matching technique is that it isolates the effects of being affiliated with the SRO (Model 4) and with trade associations (Model 5), as it removes group differences that may explain affiliation patterns, such as firm characteristics that motivate self-selection.

Model 6 incorporates voluntary actions and law violations from 2009 as additional control variables. These lagged dependent variables may capture unobserved factors or 
Table 1 Summary statistics

\begin{tabular}{lrrrr}
\hline & \multicolumn{1}{c}{$M$} & \multicolumn{1}{c}{ SD } & Min & Max \\
\hline Law violations & 1.02 & .99 & .00 & 6.00 \\
Voluntary actions & 1.47 & 1.58 & .00 & 5.00 \\
SRO & .91 & .29 & .00 & 1.00 \\
Trade associations & .61 & .49 & .00 & 1.00 \\
Employees & .89 & .70 & .00 & 7.55 \\
Sales & 4.50 & 2.22 & .00 & 9.21 \\
Product range & 2.37 & 1.34 & .00 & 5.00 \\
Damage insurance & .80 & .40 & .00 & 1.00 \\
Life insurance & .72 & .45 & .00 & 1.00 \\
Mortgage credit & .54 & .50 & .00 & 1.00 \\
Consumer credit & .30 & .46 & .00 & 1.00 \\
\hline
\end{tabular}

SRO and Trade associations are dichotomous variables indicating whether firms are affiliated with each industry actor. Sales and Employees are transformed using the natural logarithm. These statistics are based on the data used to test Model 1 (the baseline model; $N=8655)$

structural characteristics that could influence firm behavior, and which may also relate to self-selection (e.g., whether firms are structurally non-compliant). To ensure proper comparability between periods, Model 6 focuses on the nine law violations that were subject to assessment in both 2009 and 2010 (the self-assessments vary between years, so their corresponding compliance assessments do not necessarily include the same set of regulations every year). Finally, Model 7 focuses on firms that started to operate in $2010(N=$ 862). This model is used as an alternative means to reduce the possible influence of selfselection, as these firms' decision to affiliate is not influenced by prior characteristics or behaviors.

\section{Results}

The summary statistics reported in Table 1 show that $91 \%$ of the firms are affiliated with the SRO, and $61 \%$ are affiliated with trade associations. ${ }^{4}$ Firms on average take 1.47 voluntary actions, violate 1.02 laws, and sell or provide advice on 2.37 financial products. The majority of firms sell damage or life insurance, and to a lesser extent, mortgage and consumer credit. The correlation coefficients between all variables lie within -.05 and .50 , raising no concerns about multicollinearity.

\footnotetext{
4 The fact that the vast majority of firms is affiliated with the SRO likely relates to the (limited) discount SRO members get on license fees. AFM representatives informed us that the number of firms that had been expelled from the SRO is neglectable, and that a small fraction of firms preferred not to join the SRO in order to establish relationships only with the AFM. They could not provide other reasons why SRO members and non-members might differ. To mitigate the influence of possible differences between SRO members and non-members, and of possible self-selection, the analysis includes relevant firm characteristics as control variables, a matched-sample test in which pairs of firms only differ in terms of whether they are SRO members versus non-members (Model 4), and a test that controls for lagged dependent variables, which might capture more structural firm characteristics (Model 6).
} 


\section{Model 1: The Baseline Model}

The analysis includes seven models. Model 1 employs all available observations (the entire sample), and is used as the baseline model. Subsequent models are used to assess whether the results hold when we make more stringent comparisons between the two types of affiliations (Models 2-7). Each model includes two Poisson regressions, explaining voluntary actions (R1) and law violations (R2). The results of Model 1 are reported in Table 2.

To facilitate the interpretation of the results, the estimates in Table 2 are first reported as incidence ratios (IRs; for an overview on the analysis of count models in criminology, see MacDonald and Lattimore 2010). An IR can be interpreted as the factor by which the predictor changes the predicted count. IRs below, equal to, and above 1.0 are indicative of negative, null, and positive changes, respectively. The IRs in the first regression (R1) indicate that each type of affiliation is associated with a significant increase in the number of voluntary actions ( $16 \%$ for the SRO, 53\% for trade associations). The IRs in the second regression (R2) indicate that the number of law violations is reduced by $5 \%$ when the number of voluntary actions increases by one unit, and by $10 \%$ when firms are affiliated with the SRO (there is no significant direct effect for trade associations). ${ }^{5} \mathrm{We}$ elaborate more on the magnitude of the observed associations in the "Overview of the Results" section.

To properly test our hypotheses, we need to estimate the significance of the indirect effects and the differences between effects using the untransformed regression parameters, which are reported in the last two columns of Table 2. Hypothesis 1 states that ISR can be effective, independently of the degree of government intervention. Empirically, our expectation is that each type of affiliation has a negative and significant direct or indirect effect on law violations. The results provide support for our hypothesis. The estimates under R2 support a negative direct effect for the SRO $(\beta=-.107, p=.003)$, but not for trade associations ( $\beta=.047, p>.05$ ). For the two types of industry actors, however, the indirect effect through voluntary actions is negative and significant, as neither of the corresponding $95 \%$ bootstrap confidence intervals contains zero (the point estimates for the SRO and for trade associations are -.008 and -.022 , respectively).

Model 1 also provides support for our second hypothesis, which states that the direct effect is stronger for the SRO (Hypothesis 2a), and the indirect effect is stronger for trade associations (Hypothesis 2b). The effect differences are also estimated using $95 \%$ bootstrap confidence intervals, and are reported in the last rows of Table 2. The difference in direct effects is negative and significant (-.154), indicating that the direct effect is stronger (more negative) for the SRO. The difference in indirect effects is positive and significant (.014), indicating that the indirect effect is stronger (more negative) for trade associations.

With regard to model statistics, the likelihood ratios indicate that each Poisson regression is significant as a whole. The pseudo- $R^{2}$ s found in Poisson regressions are not equivalent to the $R^{2}$ s found in OLS regressions, and cannot be interpreted in the same way (i.e., as a percentage of overall explained variation; Coxe et al. 2009; Weisburd and Piquero 2008). However, pseudo- $R^{2}$ s can be used to compare models that explain the same outcome and

\footnotetext{
${ }^{5}$ To avoid confusion, we make use of the terms direct and indirect effects, which are part of the standard mediation analysis terminology. Although the theory and the subsequent robustness tests go in line with the expected direction of causality, non-experimental studies like this cannot strictly confirm effects. A conservative interpretation should, therefore, take these results as associations.
} 
Table 2 Model 1-Baseline model: Poisson regressions explaining voluntary actions (R1) and law violations (R2)

\begin{tabular}{|c|c|c|c|c|}
\hline & \multicolumn{2}{|c|}{ Incidence ratios } & \multicolumn{2}{|c|}{ Untransformed parameters } \\
\hline & $\mathrm{R} 1$ & $\mathrm{R} 2$ & $\mathrm{R} 1$ & $\mathrm{R} 2$ \\
\hline SRO & $\begin{array}{l}1.159 * * * \\
(.042)\end{array}$ & $\begin{array}{l}.898^{* *} \\
(.033)\end{array}$ & $\begin{array}{l}.148 * * * \\
(.036)\end{array}$ & $\begin{array}{l}-.107 * * \\
(.037)\end{array}$ \\
\hline Trade associations (TAs) & $\begin{array}{l}1.532 * * * \\
(.037)\end{array}$ & $\begin{array}{l}1.048 \\
(.028)\end{array}$ & $\begin{array}{l}.427 * * * \\
(.024)\end{array}$ & $\begin{array}{l}.047 \\
(.027)\end{array}$ \\
\hline Voluntary actions & & $\begin{array}{l}.950^{* * *} \\
(.007)\end{array}$ & & $\begin{array}{l}-.051^{* * *} \\
(.007)\end{array}$ \\
\hline Employees & $\begin{array}{l}1.166^{* * *} \\
(.015)\end{array}$ & $\begin{array}{l}1.043^{*} \\
(.018)\end{array}$ & $\begin{array}{l}.153^{* * * *} \\
(.013)\end{array}$ & $\begin{array}{l}.042 * \\
(.017)\end{array}$ \\
\hline Sales & $\begin{array}{l}1.079 * * * \\
(.006)\end{array}$ & $\begin{array}{l}.972 * * * \\
(.006)\end{array}$ & $\begin{array}{l}.076 * * * \\
(.005)\end{array}$ & $\begin{array}{l}-.028^{* * *} \\
(.006)\end{array}$ \\
\hline Life insurance & $\begin{array}{l}1.284 * * * \\
(.067)\end{array}$ & $\begin{array}{l}1.404 * * * \\
(.082)\end{array}$ & $\begin{array}{l}.250 * * * \\
(.052)\end{array}$ & $\begin{array}{l}.339 * * * \\
(.058)\end{array}$ \\
\hline Mortgage credit & $\begin{array}{l}1.193 * * * \\
(.051)\end{array}$ & $\begin{array}{l}1.529^{* * *} \\
(.074)\end{array}$ & $\begin{array}{l}.176^{* * * *} \\
(.043)\end{array}$ & $\begin{array}{l}.425^{* * * *} \\
(.049)\end{array}$ \\
\hline Consumer credit & $\begin{array}{l}1.174 * * * \\
(.046)\end{array}$ & $\begin{array}{l}1.374 * * * \\
(.062)\end{array}$ & $\begin{array}{l}.161 * * * \\
(.039)\end{array}$ & $\begin{array}{l}.318^{* * * *} \\
(.045)\end{array}$ \\
\hline Product range & $\begin{array}{l}.940 \\
(.030)\end{array}$ & $\begin{array}{l}.825^{* * *} \\
(.029)\end{array}$ & $\begin{array}{l}-.062 \\
(.032)\end{array}$ & $\begin{array}{l}-.192 * * * \\
(.035)\end{array}$ \\
\hline Intercept & $\begin{array}{l}.469 * * * \\
(.020)\end{array}$ & $\begin{array}{l}1.125^{* *} \\
(.048)\end{array}$ & $\begin{array}{l}-.757 * * * \\
(.043)\end{array}$ & $\begin{array}{l}.118^{* *} \\
(.043)\end{array}$ \\
\hline \multicolumn{5}{|l|}{ Model statistics } \\
\hline Likelihood ratio $\chi^{2}$ & $2284 * * *$ & $280^{* * *}$ & $2284 * * *$ & $280^{* * *}$ \\
\hline $\begin{array}{l}\text { Pseudo } R^{2} \\
N\end{array}$ & $\begin{array}{l}.074 \\
8655\end{array}$ & .012 & $\begin{array}{l}.074 \\
8655\end{array}$ & .012 \\
\hline \multicolumn{5}{|l|}{ Indirect effect $(a \cdot b)$} \\
\hline $\begin{array}{l}\text { SRO } \\
\text { Trade associations }\end{array}$ & & & $\begin{array}{l}-.008[-.013,-.003] \\
-.022[-.029,-.015]\end{array}$ & \\
\hline \multicolumn{5}{|l|}{ Effect differences } \\
\hline $\begin{array}{l}\text { Direct effect } \\
\text { Indirect effect }\end{array}$ & & & $\begin{array}{l}-.154[-.244,-.060] \\
.014[.008, .022]\end{array}$ & \\
\hline
\end{tabular}

SRO and Trade associations are dichotomous variables indicating whether firms are affiliated with each industry actor. Sales and Employees are transformed using the natural logarithm. Standard errors are in parentheses. Indirect effects and Effect differences are based on 95\% bias-corrected and accelerated bootstrap confidence intervals, using 5000 replications, which are reported in brackets. Effect differences are equal to the estimate for the SRO minus the estimate for trade associations

$* p<.05 ; * * p<.01 ; * * * p<.001$

employ the same sample (D'unger et al. 1998), as larger values are still indicative of better fit. A cautious comparison across models is presented in the "Overview of the Results" section. 
Table 2 reports McFadden's pseudo- $R^{2}$ statistics, which in this case fall below .10 . According to McFadden (1978; p. 306), pseudo- $R^{2}$ s are considerably lower than traditional $R^{2}$ s, so that values of .2 to .4 "represent excellent fit". There are different types of pseudo$R^{2}$ statistics, but in general, pseudo- $R^{2}$ s below .10 are often reported in criminology (e.g., Andersen 2015; Berg et al. 2016), including research on corporate deviance (Hunt and Topalli 2018). Again, we elaborate more on these model statistics in the "Overview of the Results" section.

The analysis controls for characteristics that relate to firm capacity and specialization, and which could potentially influence voluntary actions and compliance. The results in Table 2 indicate that the only control variable that follows the same pattern as affiliations is sales, as it is positively associated with voluntary actions and negatively associated with law violations. This goes in line with prior criminological research, and suggests that financial performance is positively associated with compliance (Keane 1993). The relationship between law violations and the other control variables (number of employees, product types, and product range) appears to be more ambiguous, as their direct and indirect associations have inconsistent signs.

\section{Models 2-7: Alternative (Robustness) Tests}

The analysis includes six additional models, which are used to assess whether the results of Model 1 hold when we make more stringent comparisons between the two types of affiliations, and when we address possible self-selection. Table 3 reports untransformed parameters of the Poisson regressions explaining voluntary actions (R1) and law violations (R2) for Models 2-7. The control variables are the same as in Model 1, but for brevity are not reported in this table. A detailed description of each model is provided in the "Analytic Strategy" section.

While Model 2 excludes firms affiliated with two or more trade associations, Model 3 excludes firms that are affiliated with both types of industry actors. In line with Hypothesis 1, Models 2 and 3 support a negative and significant direct effect for the SRO, and a negative and significant indirect effect for the two types of affiliations. Only Model 2 supports a stronger direct effect for the SRO (Hypothesis 2a). Both models support a stronger indirect effect for trade associations (Hypothesis 2b). Notably, the reduced sample size in Model 3 reveals that the majority of firms affiliated with trade associations are also affiliated with the SRO. This further justifies the use of this model, as it allows us to make a clear-cut comparison between the two types of affiliations.

To mitigate the possible influence of self-selection, we employ an exact matching technique which identifies pairs of firms that are identical across all covariates and only differ in terms of whether they are affiliated versus not affiliated with the SRO (Model 4), and affiliated versus not affiliated with trade associations (Model 5). Model 4 isolates the potential influence of the SRO, while Model 5 isolates the potential influence of trade associations. Model 4 indicates that the effect for the SRO is direct (R2: $\beta=-.190, p=.001$ ), but not indirect $(a \cdot b=.002, p>.05)$. In contrast, Model 5 indicates that the effect for trade associations is indirect $(a \cdot b=-.017, p<.05)$, but not direct ( $2: \beta=.022, p>.05)$.

Table 3 does not include effect differences for Models 4 and 5, as the regression estimates are based on pairs of quasi-identical observations, and cannot be used to make traditional estimate comparisons. Instead, we report matched-sample differences, which are one-tailed $t$ tests that compare the observed number of voluntary actions (under R1) and 


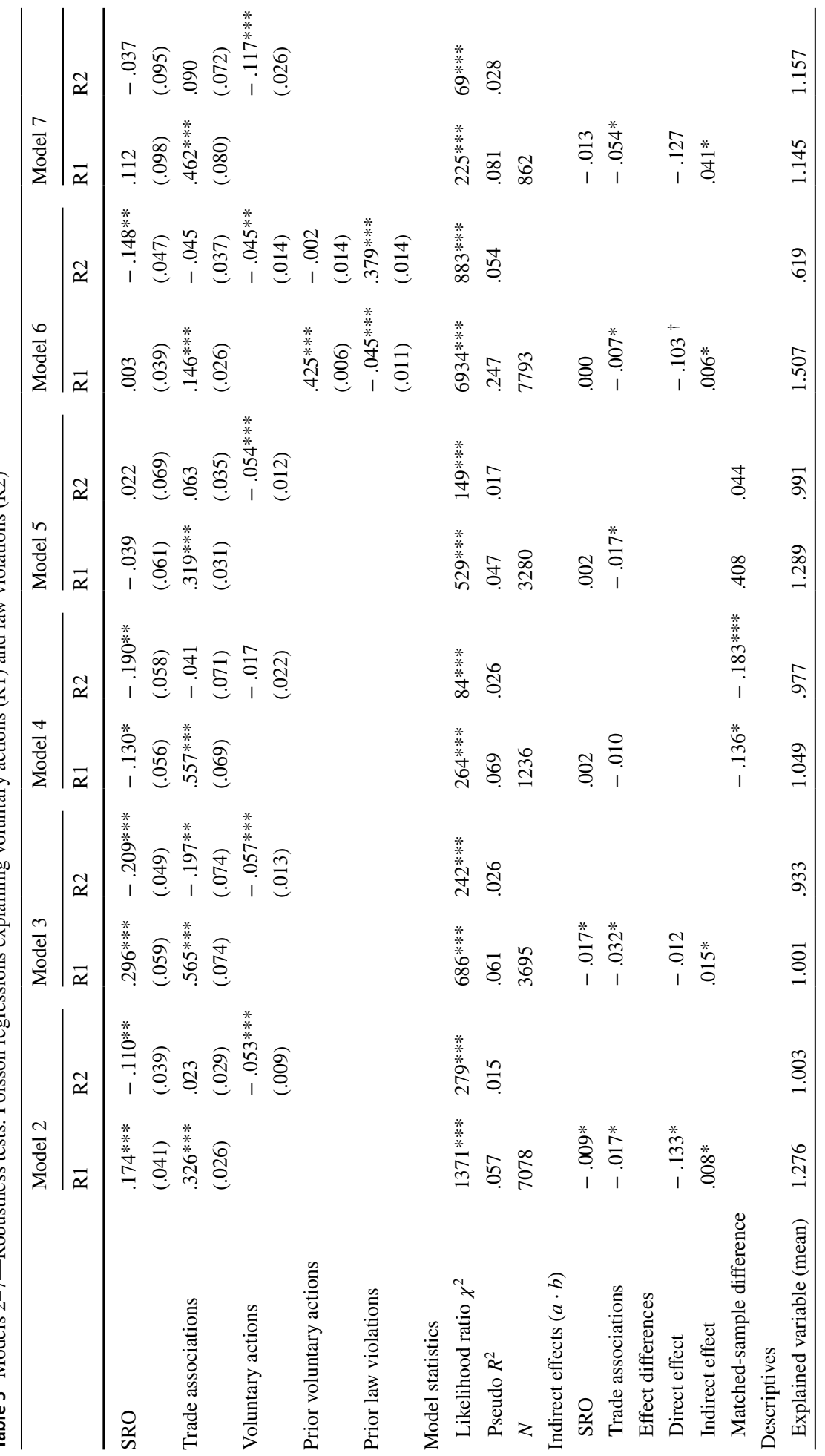




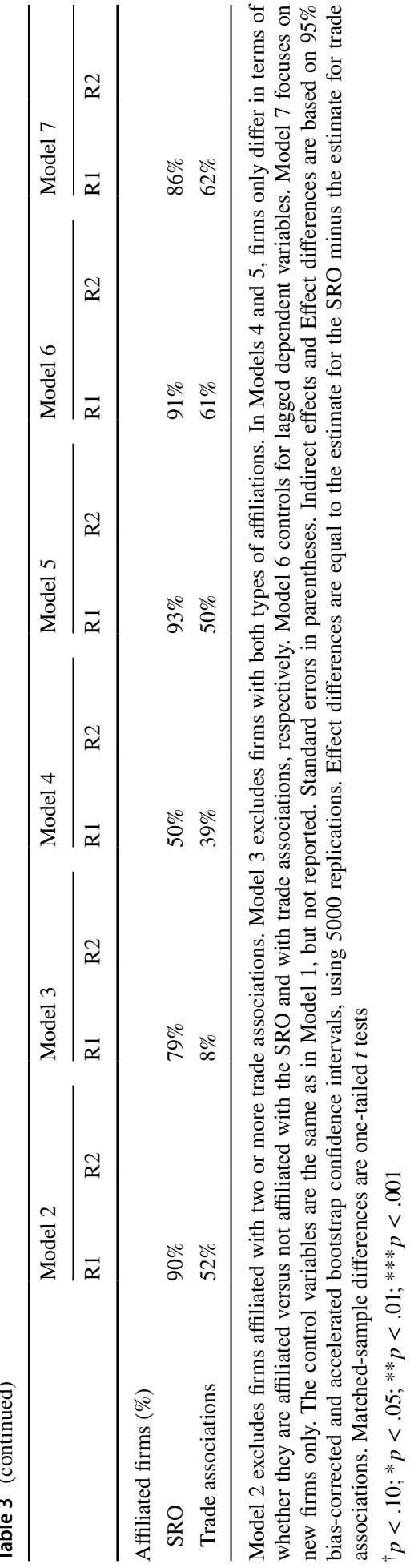


law violations (under R2) between firms that only differ in terms of their affiliation status (i.e., the matched-sample dummy). Model 4 indicates that, as compared to firms not affiliated with the SRO, firms affiliated with the SRO take .136 fewer voluntary actions $(p<.05)$, and violate 183 fewer laws $(p<.001)$. However, the association between voluntary actions and law violations is not significant (R2: $\beta=-.017, p>.05)$, indicating that there is only a negative direct effect for the SRO.

The results of Model 5 indicate that, as compared to firms not affiliated with trade associations, firms affiliated with trade associations take .408 more voluntary actions $(p<.001)$, and do not differ the number of law violations $(p>.05)$. In contrast with Model 4, however, the association between voluntary actions and law violations in Model 5 is negative and significant (R2: $\beta=-.054, p<.001)$, indicating that there is only a negative indirect effect for trade associations. In sum, Models 4 and 5 support Hypotheses 1 and 2 , and go in line with the idea that the influence exerted by each industry actor follows a different path (i.e., only a direct effect for the SRO, and only an indirect effect for trade associations).

Model 6 includes lagged dependent variables, which may capture structural firm characteristics, and may signal, for example, whether firms tend to be compliant or non-compliant. In order to have a consistent measure of compliance across periods, this model accounts for the subset of law violations that applied to both 2009 and 2010, which is why the mean number of law violations reported in the table is relatively lower than the rest. As in the prior models, Model 6 supports an association that is only direct for the SRO (R2: $\beta=-.148, p<.001)$, and only indirect for trade associations $(a \cdot b=-.007$, $p<.05)$. Crucially, these associations are significant over and above the effects of the lagged dependent variables.

The strong associations between prior and subsequent behavior, and the corresponding increments in the pseudo- $R^{2}$ statistics (as compared to Model 1), indicate that improving the level of compliance is not necessarily an immediate response. This is because of the existence of compliance costs (e.g., it is costly to setup an appropriate system to handle costumer complaints) or time constraints (e.g., obtaining a given certification requires preparations and repeated interactions). Firms deal with these challenges in different ways, and for this reason, it is important to control for relevant firm characteristics, such as sales and number of employees. Complying with a given regulation, therefore, can be easier, cheaper, or require less time for some firms than for others. Notably, when we control for these potential dynamic effects or structural firm characteristics, we still find support for the expected associations.

Model 7 focuses on firms that became active in 2010 (new firms), as a means to remove the influence of prior behavior. This model also supports an indirect effect for trade associations, but does not support an effect for the SRO. Model 7 excludes $90 \%$ of the sample, and only 120 of these new firms are affiliated with the SRO. A non-significant direct effect can be explained by drastic reductions in statistical power (Rucker et al. 2011), and in this case, by the fact that new firms have had limited time to interact with the SRO, which is characterized by relatively more formal and unidirectional communications.

\section{Overview of the Results}

Overall, being affiliated with each type of industry actor is negatively associated with law violations, although in different ways. The results tend to more clearly support a direct association only for the SRO, and an indirect association only for trade associations. The 
fact that we observe significant differences between the two types of industry actors across alternative tests suggests that they are indeed qualitatively distinct.

The obtained pseudo- $R^{2}$ s range between .047 and .247 for regressions explaining voluntary actions (R1), and between .012 and .054 for regressions explaining law violations (R2). It is reasonable to expect these low values, not only because of how these pseudo$R^{2} \mathrm{~S}$ are constructed (McFadden 1978), but also because compliance is in itself a complex construct, which can be influenced by a variety of factors (Nielsen and Parker 2012; Simpson and Rorie 2011). Empirical research on regulatory compliance is particularly challenging (Parker and Nielsen 2009), and limitations related to data availability and researchers' capacity to account for all relevant variables increase the chances of omitted variable bias. Although we identify key variables associated with compliance, significant variation in the number of law violations is not explained by the variables included in our analysis. However, not being able to explain a large part of the variance is in line with the observation that it is a difficult challenge for authorities to identify firms, based on observable characteristics, that are likely to be non-compliant. This is also consistent with the broader observation that empirical models in criminology tend to have limited explanatory power (for a discussion, see Weisburd and Piquero 2008).

A cautious comparison between the obtained pseudo- $R^{2}$ statistics-noting that these are based on different sub-samples-indicates that stringer comparisons tend to increase, rather than decrease, the model's explanatory power. This provides further support for the distinction we make between the two types of industry actors.

In order to evaluate the magnitude of the individual associations, it is relevant to take two points into consideration. The first is that these associations are observed when analyzing the entire industry, which comprises over 8000 firms. The incidence ratios in Model 1 indicate that, for instance, each additional voluntary action is associated with a $5 \%$ decrease in law violations. Given that firms take on average more than one voluntary action, these industry-wide reductions can be evaluated as considerable in magnitude. The second point is that these firms are financial intermediaries, which tend to have numerous customer relationships. Even if the effect sizes are evaluated as relatively small, it is important to underscore that they have a multiplicative effect that can reach a large number of customers. Violating on law can result in numerous delinquencies, as such advice is likely given in numerous instances. This is crucial for authorities striving to prevent disturbances that could jeopardize the stability of the economy or the financial markets (multiplicative effects associated with, e.g., the misselling of subprime mortgage loans).

\section{Discussion}

Industry self-regulation (ISR) broadly refers to the influence that industry actors (associations, organizations) exert on firm regulatory compliance. The government can intervene in this process by, for example, delegating supervisory or enforcement tasks to industry actors. The theory suggests that government intervention makes ISR more mandated and less voluntary, as it makes industry actors behave more as representatives of the authorities and rely more on deterrence.

In this study, we make use of a unique dataset that allows us to examine how government intervention may affect ISR. We first distinguish industry actors depending on whether they are subject to more versus less government intervention. We then analyze the association 
between firms' affiliations with industry actors (explanatory variable), voluntary actions aligned with regulatory compliance (e.g., requesting audits, attending workshops; mediator variable), and law violations (outcome variable). The objective is to investigate if this association changes when industry actors are subject to more versus less government intervention. The analysis employs official data from the entire financial intermediation industry in the Netherlands. Industry actors are distinguished between trade associations and the industry's self-regulatory organization (SRO), which is subject to more government intervention. The results support a negative association between being affiliated with each type of industry actor and law violations, although in different ways. The association is more more indirect for trade associations than for the SRO (i.e., it is more strongly mediated by voluntary actions). The results indicate that, under less government intervention, industry actors may promote more voluntary efforts to comply. This goes in line with the theory that ISR is more voluntary under less government intervention.

The influence of government intervention on ISR has been subject to theoretical analysis for decades. To the best of our knowledge, this is the first empirical study that compares different levels of government intervention simultaneously and in the same setting. The analysis can be considered unique also because it employs official compliance data for an entire industry. Although the results are robust and well-aligned with the theory, with the available data we are unable to confirm that these are causal associations.

\section{Limitations}

Firms with certain characteristics can be more likely to join industry organizations or associations, and for this reason, empirical studies in this area account for possible self-selection (e.g., Gamper-Rabindran and Finger 2013; Lenox and Nash 2003). Following recent research in criminology (Cochran et al. 2016; Pina-Sánchez and Linacre 2014), we make use of an exact matching technique to mitigate the potential influence of self-selection. Moreover, we control for prior voluntary actions and law violations, which may capture structural factors related to these behaviors. The results of these tests support our hypotheses. Completely eliminating self-selection, however, would require a field experiment in which firms are randomly assigned into groups of affiliated versus not affiliated firms.

It could be argued that our findings are context-dependent (that they apply only to the financial intermediation industry or only to the Netherlands), raising concerns about generalizability. The theory that we review is not exclusive to any specific industry or country. Of course, the setting that we examine has its own characteristics, but we focus on its more generalizable elements. At an abstract level, we analyze the interaction between three players: a government that can intervene, industry actors that can promote voluntary actions, and firms that decide whether to take actions and comply. Following prior theoretical work on this topic (e.g., Ashby et al. 2004; DeMarzo et al. 2005), this conceptualization applies well to a variety of settings.

A similar concern may relate to the validity of our measures. Although the dataset covers a limited set of actions and regulations, the key advantage of these measures is that they apply to all the firms in the industry (other voluntary actions and regulations may only pertain to sub-populations of firms). With the available data, we cannot fully rule out the possibility that relevant actions and regulations have been excluded from the analysis. We do note, however, that including a limited number of voluntary actions and law violations goes against - rather than in favor of-finding significant effects, especially differences between effects. 
Finally, the low pseudo- $R^{2} \mathrm{~s}$ may raise concerns about omitted variable bias, despite the fact that low values are common in criminology. There might be unobserved factors that are relevant in explaining voluntary actions and non-compliance, but these will only affect the conclusions if they are structurally associated with the hypothesized paths and differences between the two types of affiliations. The significance of the lagged dependent variables in Model 6 indicates that structural differences do affect the dependent variables, but the hypothesized effects are nevertheless significant, over and above the effects of these lagged dependent variables. This indicates that the conclusions may be unaffected by these structural factors. Evidently, the explanatory variables in our model are limited to affiliations and firm characteristics. Future studies can incorporate indicators of corporate governance, financial distress, perceived deterrence, or employee demographics - to name some examples-which in theory can influence voluntary actions and non-compliance.

\section{Conclusions}

The present analysis can contribute to discussions on intervention trade-offs (Feldman 2018). If government intervention can be at the same time directly and indirectly associated with compliance, and these associations are not necessarily aligned, authorities may question whether more intervention is necessarily better. Conceptually, when industry actors promote compliance in an autonomous or independent manner, intervening might become not only redundant or unnecessary, but also costlier for the authorities (O'Rourke 2003). This is consistent with the idea that strong deterrence can hinder voluntary compliance (Frey 1997; Mendoza et al. 2017). Government intervention can be desirable or necessary, however, when industry actors are evidently passive or ineffective. In such cases, the threat of punishment may be the only way to increase compliance. Either way, authorities may benefit from assessing when to intervene, as the outcome may not be immediately straightforward.

This leads to the question of how to evaluate industry actors. For instance, authorities could use public records on affiliations and voluntary actions (e.g., attendance to workshops or training sessions) to first assess whether industry actors are effective, and then decide how to intervene. In line with the principle of responsive regulation (Baldwin and Black 2008), authorities could design a tailor-made "intervention strategy", which varies between industry actors, depending on the extent to which each of them has the capacity to promote voluntary actions. Alternatively, authorities can use the gathered information to target audits at firms with no affiliations, or at firms affiliated with ineffective industry actors. Notably, risk profiling can be more cost-efficient when authorities gather relevant information from a few industry actors instead of thousands of firms.

For researchers, criminologists in particular, this study contributes to discussions on how group processes and social factors relate to firm compliance behavior. Future survey studies could provide further insights on how firms perceive industry actors that are subject to low versus high government intervention, and how these perceptions relate to voluntary efforts to comply. Our results indicate that the association between affiliations and law violations may well be only indirect, and this has a crucial implication for research in this area. Studies ignoring mediating factors may erroneously conclude that there is no association between certain affiliations and compliance in cases in which the association is actually indirect. 
Open Access This article is distributed under the terms of the Creative Commons Attribution 4.0 International License (http://creativecommons.org/licenses/by/4.0/), which permits unrestricted use, distribution, and reproduction in any medium, provided you give appropriate credit to the original author(s) and the source, provide a link to the Creative Commons license, and indicate if changes were made.

\section{References}

AFM (2018) About the Uutch authority for the financial markets. Accessed 01 2018. https://www.afm.nl/ en/over-afm

Andersen SH (2015) Serving time or serving the community? Exploiting a policy reform to assess the causal effects of community service on income, social benefit dependency and recidivism. J Quant Criminol 31(4):537-563

Ashby S, Chuah S-H, Hoffmann R (2004) Industry self-regulation: a game-theoretic typology of strategic voluntary compliance. Int J Econ Bus 11(1):91-106

Baldwin R, Black J (2008) Really responsive regulation. Mod Law Rev 71(1):59-94

Barnett ML, King AA (2008) Good fences make good neighbors: a longitudinal analysis of an industry self-regulatory institution. Acad Manag J 51(6):1150-1170

Bartle I, Vass P (2007) Self-regulation within the regulatory state: Towards a new regulatory paradigm? Public Adm 85(4):885-905

Berg MT, Baumer E, Rosenfeld R, Loeber R (2016) Dissecting the prevalence and incidence of offending during the crime drop of the 1990s. J Quant Criminol 32(3):377-396

Black J (2001) Decentring regulation: understanding the role of regulation and self-regulation in a 'postregulatory' world. Curr Leg Probl 54(1):103-146

Bolton P, Freixas X, Shapiro J (2007) Conflicts of interest, information provision, and competition in the financial services industry. J Financ Econ 85(2):297-330

Braithwaite J, Walker J, Grabosky P (1987) An enforcement taxonomy of regulatory agencies. Law Policy 9(3):323-351

Cochran JC, Lynch MJ, Toman EL, Shields RT (2018) Court sentencing patterns for environmental crimes: Is there a "green" gap in punishment? J Quant Criminol 34(1):37-66

Coxe S, MacKinnon DP (2010) Mediation analysis of Poisson distributed count outcomes. Multivar Behav Res 45(6):1022-1022

Coxe S, West SG, Aiken LS (2009) The analysis of count data: a gentle introduction to Poisson regression and its alternatives. J Personal Assess 91(2):121-136

Crawford A (2006) Networked governance and the post-regulatory state? Steering, rowing and anchoring the provision of policing and security. Theor Criminol 10(4):449-479

DeMarzo PM, Fishman MJ, Hagerty KM (2005) Self-regulation and government oversight. Rev Econ Stud 72(3):687-706

Drahos P, Krygier M (2017) Regulation, institutions and networks. In: Drahos P (ed) Regulatory theory: foundations and applications, chapter 1. ANU Press, Acton, pp 1-24

D'unger AV, Land KC, McCall PL, Nagin DS (1998) How many latent classes of delinquent/criminal careers? Results from mixed Poisson regression analyses. Am J Sociol 103(6):1593-1630

Fairman R, Yapp C (2005) Enforced self-regulation, prescription, and conceptions of compliance within small businesses: the impact of enforcement. Law Policy 27(4):491-519

Feldman Y (2018) The law of good people: challenging states' ability to regulate human behavior. Cambridge University Press, Cambridge

Frey BS (1997) A constitution for knaves crowds out civic virtues. Econ J 107(443):1043-1053

Gamper-Rabindran S, Finger SR (2013) Does industry self-regulation reduce pollution? Responsible Care in the chemical industry. J Regul Econ 43(1):1-30

Garvin DA (1983) Can industry self-regulation work? Calif Manag Rev 25(4):37-52

Gilad S (2010) It runs in the family: meta-regulation and its siblings. Regul Gov 4(4):485-506

Greenbaum SI, Thakor AV, Boot A (2015) Contemporary financial intermediation. Academic Press, Oxford

Gunningham N, Kagan RA (2005) Regulation and business behavior. Law Policy 27(2):213-218

Gunningham N, Rees J (1997) Industry self-regulation: an institutional perspective. Law Policy 19(4):363-414

Gupta AK, Lad LJ (1983) Industry self-regulation: an economic, organizational, and political analysis. Acad Manag Rev 8(3):416-425

Hansen LL (2009) Corporate financial crime: social diagnosis and treatment. J Financ Crime 16(1):28-40 
Haufler V (2013) A public role for the private sector: industry self-regulation in a global economy. Carnegie Endowment, Washington

Héritier A, Eckert S (2008) New modes of governance in the shadow of hierarchy: self-regulation by industry in Europe. J Public Policy 28(1):113-138

Hunt DE, Topalli V (2018) To control or be controlled: predicting types of offending in a corporate environment using control-balance theory. J Quant Criminol. https://doi.org/10.1007/s1094 0-018-9390-0

Inderst R, Ottaviani M (2009) Misselling through agents. Am Econ Rev 99(3):883-908

Keane C (1993) Impact of financial performance on frequency of corporate crime: a latent variable test of strain theory. Can J Criminol 35:293-308

King AA, Lenox MJ (2000) Industry self-regulation without sanctions: the chemical industry's Responsible Care Program. Acad Manag J 43(4):698-716

Lenox MJ (2006) The role of private decentralized institutions in sustaining industry self-regulation. Organ Sci 17(6):677-690

Lenox MJ, Nash J (2003) Industry self-regulation and adverse selection: a comparison across four trade association programs. Bus Strat Environ 12(6):343-356

MacDonald JM, Lattimore PK (2010) Count models in criminology. In: Piquero AR, Weisburd D (eds) Handbook of quantitative criminology. Springer, New York, NY, pp 683-698

MacKinnon DP, Fairchild AJ, Fritz MS (2007) Mediation analysis. Ann Rev Psychol 58:593-614

Maxwell JW, Lyon TP, Hackett SC (2000) Self-regulation and social welfare: the political economy of corporate environmentalism. J Law Econ 43(2):583-618

May PJ (2005) Regulation and compliance motivations: examining different approaches. Public Adm Rev 65(1):31-44

McFadden D (1978) Quantitative methods for analyzing travel behavior of individuals: some recent developments. In: Hensher D, Stopher P (eds) Behavioural travel modelling. Croom Helm, New Haven, pp 279-318

Mendoza JP, Wielhouwer JL, Kirchler E (2017) The backfiring effect of auditing on tax compliance. J Econ Psychol 62:284-294

Nielsen VL, Parker C (2012) Mixed motives: economic, social, and normative motivations in business compliance. Law Policy 34(4):428-462

Nunez J (2001) A model of self-regulation. Econ Lett 74(1):91-97

O'Rourke D (2003) Outsourcing regulation: analyzing nongovernmental systems of labor standards and monitoring. Policy Stud J 31(1):1-29

Parker C, Nielsen V (2009) The challenge of empirical research on business compliance in regulatory capitalism. Ann Rev Law Soc Sci 5:45-70

Parker C, Nielsen VL (2011) Explaining compliance: business responses to regulation. Edward Elgar Publishing, Cheltenham

Pfarrer MD, Smith KG, Bartol KM, Khanin DM, Zhang X (2008) Coming forward: the effects of social and regulatory forces on the voluntary restatement of earnings subsequent to wrongdoing. Organ Sci 19(3):386-403

Pina-Sánchez J, Linacre R (2014) Enhancing consistency in sentencing: exploring the effects of guidelines in England and Wales. J Quant Criminol 30(4):731-748

Preacher KJ (2015) Advances in mediation analysis: a survey and synthesis of new developments. Ann Rev Psychol 66:825-852

Rucker DD, Preacher KJ, Tormala ZL, Petty RE (2011) Mediation analysis in social psychology: current practices and new recommendations. Soc Personal Psychol Compass 5(6):359-371

Schell-Busey N, Simpson SS, Rorie M, Alper M (2016) What works? A systematic review of corporate crime deterrence. Criminol Public Policy 15(2):387-416

Short JL, Toffel MW (2010) Making self-regulation more than merely symbolic: the critical role of the legal environment. Adm Sci Q 55(3):361-396

Simpson SS, Rorie M (2011) Motivating compliance: economic and material motives for compliance. In: Parker C, Nielsen VL (eds) Explaining compliance: business responses to regulation. Edward Elgar Publishing, Cheltenham, pp 59-77

Sinclair D (1997) Self-regulation versus command and control? Beyond false dichotomies. Law Policy 19(4):529-559

Tyler TR (2011) The psychology of self-regulation: normative motivations for compliance. In: Parker C, Nielsen VL (eds) Explaining compliance: business responses to regulation. Edward Elgar Publishing, Cheltenham, pp 78-102

Weisburd D, Piquero AR (2008) How well do criminologists explain crime? Statistical modeling in published studies. Crime Justice 37(1):453-502 
Wenger E (1999) Communities of practice: learning, meaning, and identity. Cambridge University Press, Cambridge

Wotruba TR (1997) Industry self-regulation: a review and extension to a global setting. J Public Policy Market 1:38-54

Zhao X, Lynch JG Jr, Chen Q (2010) Reconsidering Baron and Kenny: Myths and truths about mediation analysis. J Consum Res 37(2):197-206

Publisher's Note Springer Nature remains neutral with regard to jurisdictional claims in published maps and institutional affiliations. 